\title{
Geochemical study of Arima hot-spring waters, Hyōgo, Japan, by means of tritium and deuterium
}

\author{
Kiriko TanaKa*, Morito Koizumi**, Riki Seki and Nagao Ikeda \\ Institute of Chemistry, Tsukuba University, Sakura-mura, Ibaraki 305, Japan
}

(Received January 12, 1984: Accepted May 15, 1984)

\begin{abstract}
Tritium, deuterium and chloride concentrations in the Arima hot spring waters were measured as a clue to their origin and subsurface behavior. T-D-Cl- relationships clearly indicate that the saline brine of deep origin $\left(\mathrm{T}=0 \mathrm{TR}, \delta \mathrm{D}=-30 \%\right.$ and $\left.\mathrm{Cl}^{-}=43 \mathrm{~g} / \mathrm{l}\right)$ is mixed with young meteoric water having $\mathrm{T}=30 \mathrm{TR}$, $\delta \mathrm{D}=-50 \% 0$ and $\mathrm{Cl}^{-}=0 \mathrm{~g} / 1$ in varying proportions to form a group of high chloride hot spring waters. The young meteoric water in a shallow aquifer is also mixed with the older meteoric water in a deeper aquifer characterized by high tritium concentration ( 100TR), forming another group of low chloride waters. The mixing ratio of the two meteoric waters varies with season.
\end{abstract}

\section{INTRODUCTION}

Atmospheric thermonuclear bomb tests were carried out from 1952 mainly in the northern hemisphere. Consequently tritium concentration in the atmosphere until 1961 was estimated to have reached 100 times as high as that of the normal natural level. Most of tritium atoms produced in the upper atmosphere, present in the form of HTO molecules, are incorporated into the water-circulation system including the stratosphere, troposphere and surface water reservoirs. Such bomb-produced tritium and cosmogenic one as well have been utilized in a variety of hydrological investigations since the time of its discovery (for example, von BUTTLAR and WendT, 1958; ERIKSSON, 1958; IAEA, 1967; BRown, 1961; IAEA, 1974).

The measurement of tritium concentration in hot spring waters would, thus, provide us with useful information on the origin and subsurface behavior of hot spring waters. As the half-life of tritium is about 12.43 years, it is feasible in favorable circumstances to estimate the residence time of hot spring waters through tritium measurements. In the early phase of the studies tritium determination in hot spring waters has been expected to be quite useful (for example, BEgEMANN and LibBy, 1957; Davis et al., 1967; THEODORRSON, 1967; TAGUCHI and TsuKadA, 1972; IKEDA et al., 1973). In this paper we investigate the origin and subsurface behavior of hot spring waters from the Arima district, Hyogo, Japan, by combining tritium data with deuterium and chloride concentrations.

Arima hot springs have long been the subject of a variety of geochemical investigations, since highly saline water is suggested to exist underneath. The chloride concentration of $43.7 \mathrm{~g} / 1$ (IKEDA, 1955) is the highest chlorinity ever reported for thermal waters in Japan. Stable isotope studies have shown that the saline water is mixed with local meteoric water in various proportions to give the hot spring waters (Matsubaya et al., 1974; Sakai and Matsubaya, 1974). Since tritium content of the deep saline water is expected to be zero, measurements of tritium, deuterium and chloride concentrations of the hot spring waters would make possible the estimation of chemistry of the deep-seated

* Present address: Division of Environmental Health, National Institute of Radiological Sciences, Anagawa, Chiba 260, Japan.

** Present address: Division of Research and Laboratories, IAEA, P.O. Box 200, A-1400 Vienna, Austria. 
brine that has not been contaminated by the local groundwater by extrapolating the T-D-Clrelationships to $0 \mathrm{TR}$.

\section{Samples and Experimental Procedures}

Arima district Arima spa is located to the north of the Rokko mountains in Hyogo Prefecture, Japan (Fig. 1). Granite, quartz trachyte and the Tertiary formation constitute the Arima district. Figure 1 shows the locations of the sampling sites in the area. The Taki-gawa river and Rokkō-gawa river come from Rokkō mountains which are located on the south of the Arima district. The two rivers join to constitute the Arima-gawa river and it flows to the north. High temperature, high salinity hot springs occur in a narrow region near the junction of these two rivers. At the foot of the Mt. Iba, low temperature carbonate springs discharge in a swarm.

Water samples were collected twice in June 1973 and April 1974, for which deuterium, tritium and chloride concentrations were measured.

A few liters each of hot spring and river waters was sampled into a polyethylene bottle. The temperature and $\mathrm{pH}$ values of water samples were measured in situ. For $\mathrm{D} / \mathrm{H}$ ratio determinations, five milligrams of the sample water was reduced completely to hydrogen gas by passing the water vapor over metallic uranium heated to $750^{\circ} \mathrm{C}$. The deuterium concentration of the hydrogen gas was measured on a mass-spectrometer, Hitachi, RMD. The $\mathrm{D} / \mathrm{H}$ ratio of the hydrogen is expressed in $\delta$ value, which is a permil deviation of the $\mathrm{D} / \mathrm{H}$ ratio of the sample from that of SMOW (Standard Mean Ocean Water), defined as follows,

$$
\delta \mathrm{D}=\frac{(\mathrm{D} / \mathrm{H})_{\text {sample }}-(\mathrm{D} / \mathrm{H})_{\text {SMOW }}}{(\mathrm{D} / \mathrm{H})_{\text {SMOW }}} \times 1000(\%) .
$$

Analytical error is within $\pm 1 \%$ for $\delta \mathrm{D}$ in terms of the standard deviation.

Since the tritium concentration in most of the samples is usually very low for the direct activity measurement, enrichment of tritium by

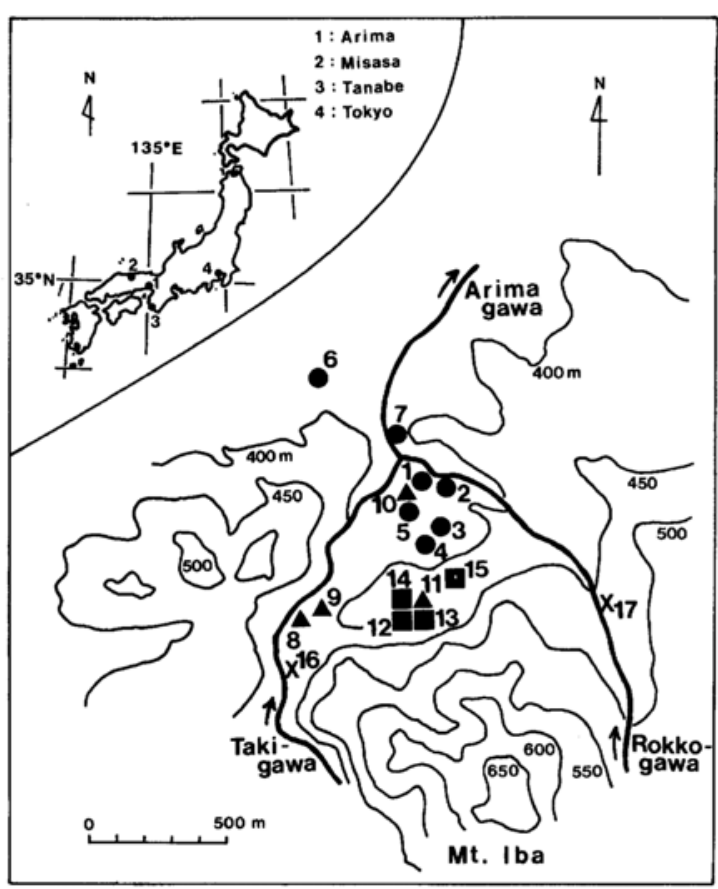

Fig. 1. Sampling localities in the Arima district. Numbers correspond to those in Table 1.

- : High-chloride hot spring waters

ه : Medium chloride hot spring waters

- : Carbonate spring waters

$\mathrm{X}$ : River water

electrolysis was carried out. The sample water was first distilled. The presence of volatile components such as hydrogen sulfide and hydrochloric acid in the sample water, which cannot be eliminated sufficiently by distillation, would cause corrosion of electrodes to influence the fractionation of $\mathrm{T} / \mathrm{H}$ ratio during the electrolytic enrichment. In such cases, freshly prepared $\mathrm{Ag}_{2} \mathrm{CO}_{3}$ powder was added to the sample water to remove both $\mathrm{S}^{2-}$ and $\mathrm{Cl}^{-}$as $\mathrm{Ag}_{2} \mathrm{~S}$ and $\mathrm{AgCl}$, respectively. The acid samples were at the same time neutralized by addition of $\mathrm{Ag}_{2} \mathrm{CO}_{3}$. The endpoint of neutralization is recognized by yellow coloration of gray precipitation which adsorbs excess $\mathrm{Ag}_{2} \mathrm{CO}_{3}$.

The tritium concentration of the electrolyzed sample was enriched about 70 times as high as the original concentration after twostage electrolyses. The details of enrichment techniques have been reported elsewhere (IKEDA 
et al., 1973). The activity of enriched tritium was measured with a liquid scintillation counter Aloka LSC-601 using "Instagel" as a scintillator. Tritium concentration was expressed in TR unit, which is defined as follows,

$$
\begin{aligned}
1 \mathrm{TR} & =(\mathrm{T} / \mathrm{H}) \times 10^{18} \quad \text { (atomic ratio) } \\
& =3.23 \mathrm{pCi} / 1 \mathrm{H}_{2} \mathrm{O} .
\end{aligned}
$$

Accuracy is within $\pm 10 \%$ of the observed value.

Chrolide concentration was measured by the Mohr's method.

\section{RESUlTS AND DiscusSion}

A number of chemical investigations have been done on the Arima hot spring waters. The highest chloride concentration of the Japanese hot spring waters was observed for the Arima waters, that was twice as high as that of sea water (IKEDA, 1955). Magmatic origin for such chloride-rich waters was suggested (NAKAmURA, 1962). Based on the extensive measurements on $\delta \mathrm{D}, \delta^{18} \mathrm{O}, \delta^{13} \mathrm{C}$ values and other chemical compositions of hot spring waters in Arima,

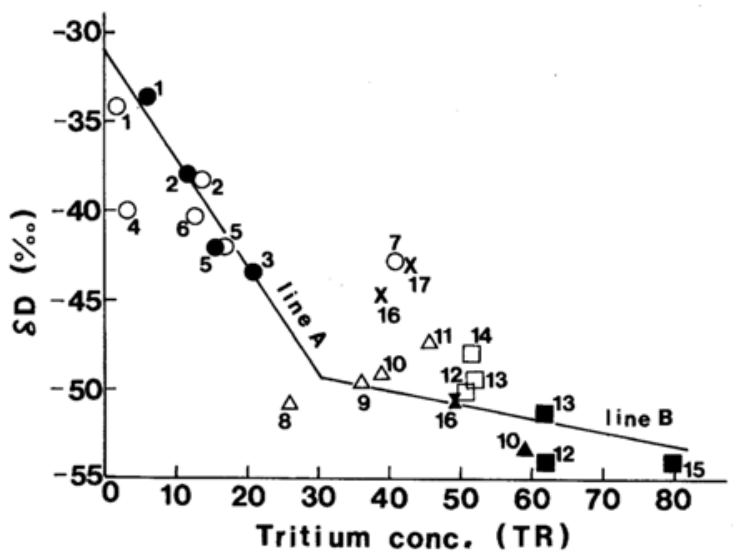

Fig. 2. Relationship between $\delta D$ value and tritium concentration in water samples from the Arima district. (Solid symbols and open symbols showing samples collected in June, 1973 and in April, 1974, respectively.) Numbers correspond to those in Table 1.

- : High-chloride hot spring waters

$\Delta \Delta$ : Medium chloride hot spring waters

口 : : Carbonated spring waters

X $\mathbf{x}$ : River waters
Matsubaya et al. $(1973,1974)$ gave detailed discussion on the origin which will be mentioned later.

The analytical results on tritium, deuterium and chloride concentrations are given in Table 1. The TR values are plotted against $\delta \mathrm{D}$ values in Fig. 2. In Fig. 3, TR values are plotted against chloride concentration. In Fig. 4, relationship between $\delta \mathrm{D}$ values and chloride concentration is shown.

From Table 1, Figs. 2 and 3, the following features can be found.

1) Six high temperature, chloride-rich hot spring waters (\#1-\#6) except Tamotoishi (\#7) have high $\delta \mathrm{D}$ values of $-34 \sim 43 \%$ and low tritium concentrations of 2 21 TR.

2) Four hot spring waters of medium chloride concentrations, (\#8-\#11) have medium tritium concentrations of $26 \sim 59 \mathrm{TR}$, and $\delta \mathrm{D}$ values of about $-50 \%$.

3) Four cold carbonate spring waters (\#12\#15) have higher tritium concentrations of $51 \sim 80 \mathrm{TR}$, and low $\delta \mathrm{D}$ values of about $-48 \sim-54 \%$.

4) In Fig. 2, a straight line (A) can be drawn through the points for five chloride-rich hot

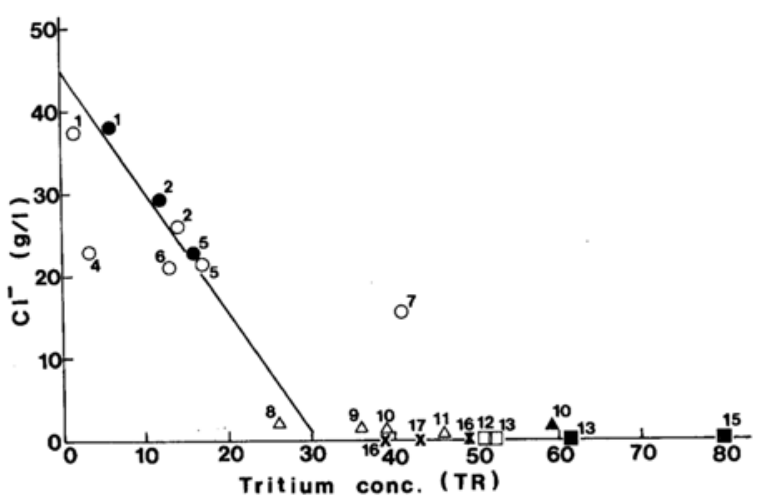

Fig. 3. Relationship between tritium and chloride concentration in water samples from the Arima district. (Solid symbols and open symbols showing samples collected in June, 1973 and in April, 1974, respectively.) Numbers correspond to those in Table 1.

$\circ \bullet$ : High-chloride hot spring waters

$\Delta \boldsymbol{\Delta}$ : Medium chloride hot spring waters

ㅁ : Carbonate spring waters

X $\mathbf{x}$ : River waters. 
Table $1 . \delta D$ values, tritium and chloride concentrations of water samples from the Arima district

\begin{tabular}{|c|c|c|c|c|c|}
\hline Sample No. & $t^{\circ} \mathrm{C}$ & $\mathrm{pH}$ & $\delta \mathrm{D}(\% 0)$ & Tritium (TR)** & $\mathrm{Cl}^{-}(\mathrm{g} / \mathrm{l})$ \\
\hline \multicolumn{6}{|l|}{ High $\mathrm{Cl}^{-}$spring water } \\
\hline 1 Tenmangū & 94.5 & 6.0 & -34.2 & $1.7(0,3.5)$ & 37.3 \\
\hline Tenmang $\overline{\mathrm{u}}^{*}$ & 92 & n.d. & -33.7 & $6.1(5.7,6.4)$ & 37.9 \\
\hline 2 Ariake & 96 & 6.6 & -38.3 & $14(13,14)$ & 26.0 \\
\hline Ariake* & 97 & n.d. & -37.9 & $12(11,12,14)$ & 29.2 \\
\hline 3 Uwanari & 91 & 6.8 & -40.1 & n.d. & 24.1 \\
\hline Uwanari* & 88 & n.d. & -43.4 & $21 \quad(19,21,23)$ & n.d. \\
\hline 4 Gokuraku & 79.5 & 6.8 & -40.4 & $3.3(3.3,3.3)$ & 23.0 \\
\hline 5 Gosho & 81.5 & 6.6 & -41.9 & $17(17,17)$ & 21.3 \\
\hline Gosho* & 89 & n.d. & -42.0 & $16(16,16)$ & 22.6 \\
\hline 6 Jadani & 8.0 & n.d. & -40.3 & $13 \quad(12,13)$ & 20.9 \\
\hline 7 Tamotoishi & 52.5 & 6.4 & -42.8 & $41 \quad(35,48)$ & 15.5 \\
\hline \multicolumn{6}{|l|}{ Low $\mathrm{Cl}^{-}$spring water } \\
\hline 8 Daihatsu & 14 & 5.2 & -50.8 & $26 \quad(22,30)$ & 2.21 \\
\hline 9 Jintan & 14.5 & 5.4 & -49.5 & $36 \quad(35,36)$ & 1.53 \\
\hline 10 Ginsen & 39 & 5.2 & -49.0 & $39 \quad(31,47)$ & 1.38 \\
\hline Ginsen* & 50 & n.d. & -53.3 & $59 \quad(58,59)$ & 1.56 \\
\hline 11 Kanihoken & 19 & 5.6 & -47.4 & $46 \quad(45,46)$ & 0.91 \\
\hline \multicolumn{6}{|l|}{ Carbonated spring water } \\
\hline 12 Sakae-I & 16 & 4.8 & -50.1 & $51 \quad(47,54)$ & 0.03 \\
\hline 13 Sakae-II & 15.6 & 5.2 & -49.4 & $52 \quad(50,54)$ & 0.01 \\
\hline Sakae-I* & 18 & n.d. & -54.1 & $62 \quad(59,65)$ & 0.0 \\
\hline Sakae-II* & 17 & n.d. & -51.3 & $62 \quad(59,05)$ & 0.0 \\
\hline 14 Jigokudani & 14 & 4.4 & -48.0 & $52 \quad(51,53)$ & n.d. \\
\hline 15 Tansan Hotel* & 17 & n.d. & -54.2 & $80 \quad(73,81,85)$ & 0.0 \\
\hline \multicolumn{6}{|l|}{ River water } \\
\hline 16 Taki river & 7.5 & 5.0 & -44.6 & $39 \quad(34,43)$ & 0.0 \\
\hline Taki river* & 17 & n.d. & -50.5 & $49 \quad(43,52,53)$ & 0.0 \\
\hline 17 Rokkō river & 13 & 5.4 & -43.1 & 43 (43) & 0.0 \\
\hline
\end{tabular}

* : Sampled in June 1973, the others collected in April 1974.

** : Mean values of duplicate or triplicate analyses given in parentheses.

n.d. : Not determined.

springs, \#1, 2, 3, 5, 6, except \#4 and \#7.

5) In Fig. 2, another line (B) can be drawn through the points for the carbonate springs, which crosses the line A at about $\mathrm{T}=30 \mathrm{TR}$, and $\delta \mathrm{D}=-50 \%$.

6) In Fig. 3, a straight line can be drawn through the points for four chloride-rich hot springs, \#1, \#2, \#5 and \#6, except \#4 and \#7.

It is suggested from Fig. 2 that chloride-rich hot spring waters result from the mixing of two types of water, viz., one having $\delta \mathrm{D}$ of $-30 \%$ and no tritium, and the other having $\delta \mathrm{D}$ of $-50 \%$ and tritium concentration of about 30TR. It is also suggested from Fig. 3 that chloride-rich hot spring waters are mixtures of two sorts of water, viz., one having $\mathrm{Cl}^{-}$concen- tration of $43 \mathrm{~g} / 1$ with no tritium, and the other is ground water which has no chloride with tritium concentration of about $30 \mathrm{TR}$. It is very likely that water of deep origin has no tritium, and hence we can conclude that one of the end members is derived from the deep water characterized by no tritium, $\mathrm{Cl}^{-}$of $43 \mathrm{~g} / 1$ and $\delta \mathrm{D}$ of $-30 \%$. The other water is the local ground water which has $\delta \mathrm{D}$ of $-50 \%$ tritium concentration of about 30TR and practically no chloride. In Fig. 4, the observation mentioned above is demonstrated again as follows: A straight line is drawn from the point of $\delta \mathrm{D}=$ $-30 \%, \mathrm{Cl}^{-}=43 \mathrm{~g} / 1$ to the point of $\delta \mathrm{D}=$ $-50 \%, \mathrm{Cl}^{-}=0 \mathrm{~g} / \mathrm{l}$, on which all the chloriderich hot spring waters lie quite well. IKEDA (1949 a, b) and MiYAKE et al. (1955 a, b) have 
already indicated on the basis of chemical studies that hot springs in the Arima district were formed by mixing of two water sources.

Matsubaya et al. (1973, 1974) demonstrated that the linear relationship between chloride concentrations and $\delta^{18} \mathrm{O}$ values holds for these hot spring waters. They also reported the linear relationship between chloride concentrations and $\delta \mathrm{D}$ values for these waters. MATSUBAYA et al. (1973, 1974) concluded that the local meteoric water was mixed with the saline brine $\left(\mathrm{Cl}^{-}=43.7 \mathrm{~g} / \mathrm{l}, \delta \mathrm{D}=-30 \sim\right.$ $-25 \%$ and $\delta^{18} \mathrm{O}=+8 \%$ ) which was considered to be in oxygen isotopic exchange equilibrium with country rocks. They considered that the

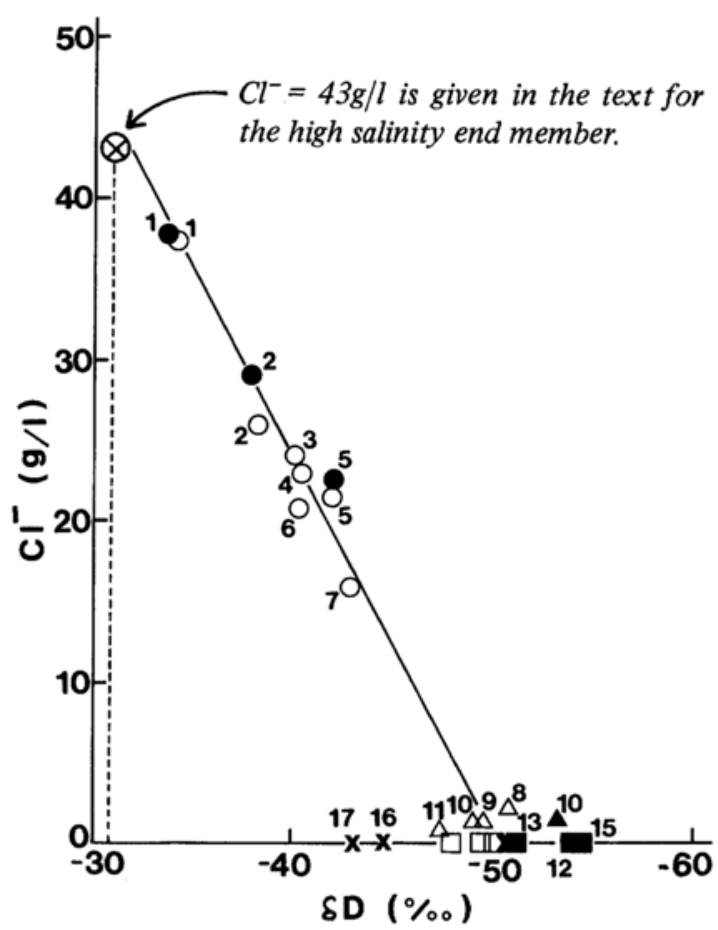

Fig. 4. Relationship between $\delta D$ and chloride concentration in water samples from the Arima district. (Solid and open symbols showing samples collected in June, 1973 and in April, 1974, respectively.)

Numbers correspond to those in Table 1.

$\circ \bullet$ : High-chloride hot spring waters

$\triangle \boldsymbol{\Delta}$ : Medium chloride hot spring waters

- - : Carbonate spring waters

$\mathrm{x} \mathbf{x}$ : River waters. saline brine most likely came from the "residual magmatic or metamorphic or geothermal" fluids associated with intrusion of the upper Cretaceous rhyolytic and granitic rocks. They also suggested another possibility that the saline brine was derived from formation water. When meteoric water penetrates into porous piles in marine formations of the Osaka basin, both $\mathrm{D} / \mathrm{H}$ and salinity would increase. On the other hand, NAKAMURA and MAYEDA (1958) proposed a possibility to form such saline brine by condensation of steam and volatile components emanated from granitic magma in the Tertiary period. They also mentioned that emanated $\mathrm{CO}_{2}$ and $\mathrm{Cl}^{-}$ascend to the surface to be dissolved in ground water, which results in cold carbonated springs.

Information obtained in these studies do not yet provide us with sufficient evidence to conclude which mechanism is appropriate. Accepting the assumption that the deep saline brine contains no tritium, we can estimate the chemical and isotopic natures of the saline water by extrapolating $\mathrm{Cl}^{-}-\mathrm{T}$ or $\delta \mathrm{D}-\mathrm{T}$ relationships to OTR.

As seen in Figs. 2 and 3, two chloride-rich hot springs (Gokuraku (\#4) and Tamotoishi (\#7)) do not fall on the mixing line as they do in Fig. 4. Since they fall on the line of $\delta \mathrm{D}$ versus chloride concentration plot, they must have resulted from mixing of two types of water. In the case of Gokuraku hot spring (\#4), the water is suggested to have been aged after mixing. It is also possible that the Gokuraku hot spring is formed by mixing of two sorts of water, chloride-rich water and old meteoric water of $\delta \mathrm{D}=$ $-50 \%$ and $\mathrm{T}=2 \sim 3 \mathrm{TR}$. The sporadic or patchlike occurrence of old meteoric water, however, is unrealistic. So that this may be ruled out. Tamotoishi hot spring water (\#7), on the contrary, can be considered to be contaminated by meteoric water of high tritium concentration. It discharges on the other side of the Rokkō river, apart from the other chloride-rich hot springs (Fig. 1), so that the meteoric water may have been derived from other hydrological unit.

As for the other end-member for the water 
mixing, the ground water with $\delta \mathrm{D}$ value of $-50 \%$ and tritium concentration of about $30 \mathrm{TR}$ is reasonable as the water source. Daihatsu (\#8), Jintan (\#9), Ginsen (\#10) and Kanihoken (\#11) hot springs belong to this category as shown in Fig. 2. As seen in Figs. 2 and 3, there is a group of waters with low chloride concentration, and variable TR values. These waters are considered to be mostly of meteoric origin. It is difficult, however, to determine the real "age" of these waters, because each hot spring water has been mixed to some extent before discharge. KUSAKABE et al. (1970) reported that $\delta \mathrm{D}$ and $\delta^{18} \mathrm{O}$ values of mountainous stream water did not change with time from the values almost identical with the annual averages of precipitation even after a heavy rain. They concluded that such mountainous stream waters are derived mostly from a wellmixed subsurface reservoir. In order to get the residence time of hot spring water, we have to know first whether or not the water is a mixture of two or more different waters. The relationship between $\delta \mathrm{D}$ versus $\mathrm{Cl}^{-}$content is suitable for this purpose. If no mixing is indicated as shown by the group of waters on the abscissa in Fig. 4, we must take care of the difference in tritium concentration in each spring water caused by the age effect. So, we next compare the tritium concentrations in rain water and in the hot spring waters.

There is some difficulty in the assessment of annual tritium input to groundwater: The input of bomb-produced tritium onto the earth varied drastically during the past two decades. Figure 5 shows the change with time (from 1961 to 1975) in the average value of tritium concentrations in precipitation in Tokyo weighted for the precipitation amount, based on the data reported by IAEA (1969, 1970, 1971, 1973, 1975, 1979). Recently, some tritium data were reported for precipitation from eleven districts in Japan in around 1976 (TsuNOGAI et al., 1982). According to them, there is appreciable difference in tritium concentration in rain between Tokyo, Misasa (western Japan along the Sea of Japan), and Tanabe (south-central Japan on the Pacific side) (see Fig. 1), regardless of large geographical distance between them spanning from 120 to $700 \mathrm{~km}$. Therefore, it would be safe to postulate that the annual mean of tritium concentration in precipitation in the Arima district is not much different from those in Tokyo given in the IAEA reports. It is clearly seen in Fig. 5 that the precipitation in Tokyo had a maximum TR value of 800 in 1963 with gradual decrease to $90 \mathrm{TR}$ in 1967 , eight years before the sampling time (1973 and 1974), and then has maintained fairly constant values at 70 80 TR until 1971. Since around 1972 the tritium concentration in rain was about $30 \mathrm{TR}$ on the average.

Figure 2 suggests that the ground water with tritium concentration of about $30 \mathrm{TR}$ is mixed with saline brine, and that this meteoric water is also the source of the Daihatsu (\#8) and Jintan (\#9) waters. This water corresponds to the latest rain water that was supplied to the ground until the sampling time. Tritium concentrations of hot spring waters on the other end of the line B in Fig. 2 can be compared with those for the meteoric water with age less than eight years at 1974 (See Fig. 5).

Ginsen (\#10), Sakae-I (\#12) and Sakae-II (\#13) waters sampled on two different dates showed different analytical results. Tritium contents of the samples collected in April (1974) were by about 10TR lower than those of the samples collected in June. The well of

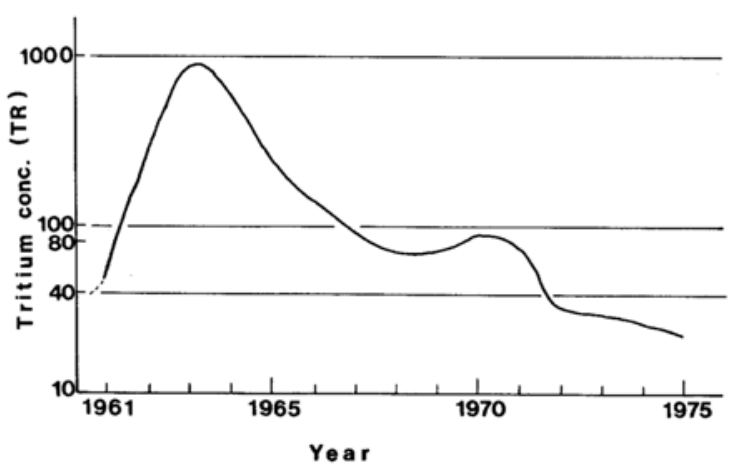

Fig. 5. Secular variation in the weighted mean values of tritium concentration in precipitation in Tokyo. 
Tansan Hotel (\#15) ceased to discharge in April 1974, so that we could not collect samples. This well often stops discharging in April, indicating that the water head which controls the discharge rate of subsurface water in this area changes seasonally. This means that the ground water level becomes lower in April than in June. Recovery of the water level in June may indicate that contribution of older water with higher tritium content in the lower layer becomes larger.

To explain this observation, we postulate that there are two ground water sources, one from a shallow aquifer and the other from a deeper aquifer, of which tritium concentrations are 30TR and $\sim 100 \mathrm{TR}$, respectively, with $\delta \mathrm{D}, \delta^{18} \mathrm{O}$ and $\mathrm{Cl}^{-}$values being almost the same. In this connection, we may note that the contribution of older water causes the increase in tritium concentration of discharging water. Based on the data of the change in weighted mean tritium concentration in rain water (Fig. $5)$, the shallow ground water with tritium content of $30 \mathrm{TR}$ is considered to correspond to the latest rain water and the deeper water with $100 \mathrm{TR}$ refers to the rain water with ages of at least eight years at the time when the sampling was made. Under this postulation, the data points along the line B in Fig. 2 can be explained as a result of the change in the mixing ratio of

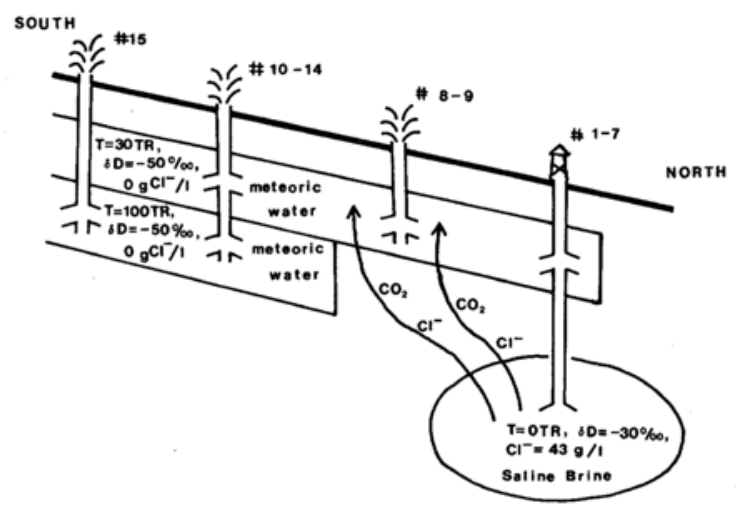

Fig. 6. A schematic presentation of the Arima hot spring waters. Numbers correspond to samples in Table 1. two kinds of ground water mentioned above. Furthermore, the seasonal change in tritium content of a few hot spring waters may also be explained in a similar fashion. The origin of carbonate and chloride in these hot spring waters is inferred to be emanation from saline brine. We can consider a model that splash from boiling saline brine clambers up and mixes to the ground water.

Although some ambiguity still remains, we can conclude some features with respect to the origin of waters in the Arima hot springs: First, as shown schematically in Fig. 6, saline brine is mixed with ground water of $30 \mathrm{TR}$ originated from the latest rain water of the age within a few years. The mixing ratio is different for each discharging water (\#1-7). Secondly, ground water of about 30TR tritium spouts out (\#8-9), in which $\mathrm{CO}_{2}$ and $\mathrm{Cl}^{-}$are enriched originally emanated from saline brine. Thirdly, the high tritium deeper ground water of the age of at least over eight years is mixed with young ground water of about 30TR tritium (\#10-15). The mixing ratio of the two types of ground water changes with season, as indicated by seasonal change in water level.

Acknowledgements-The authors wish to thank Professor SADAO MATSUO, Department of Chemistry, Faculty of Science, Tōkyō Institute of Technology, for his kind discussions and giving them opportunity to use the massspectrometric equipments.

\section{REFERENCES}

BegemanN, F. and LibBY, W. F. (1957) Continental water balance, ground water inventory and storage times, surface ocean mixing rates and world-wide water circulation patterns from cosmic-ray and bomb tritium. Geochim. Cosmochim. Acta 12, 277-296.

BROWN, R. M. (1961) Hydrology of tritium in the Ottawa Valley. Geochim. Cosmochim. Acta 21, 199-216.

BUTTLAR, H. v. and WENDT, I. (1958) Ground-water studies in New Mexico using tritium as a tracer. Trans. Am. Geophys. Union 39, 660-668.

DAVIS, G. H., DINCER, T., FLORKOWSKI, T., PAYNE, B. R. and GATTINGER, T. (1967) Seasonal variations in the tritium content of groundwaters of the 
Vienna basin, Austria (SM-83/32). Isotopes in hydrology, IAEA, 451-467.

ERIKSSON, E. (1958) The possible use of tritium for estimating groundwater storage. Tellus 10, 472-478.

IAEA (1967) Isotopes in hydrology. Proceedings of the symposium on isotopes in hydrology, 1966.

IAEA $(1969,1970,1971,1973,1975,1979)$ Environmental isotope data Nos. 1-6: World Survey of Isotope Concentration in Precipitation. Technical Reports Series Nos. 96, 117, 129, 147, 165, 192.

IAEA (1974) Isotope techniques in groundwater hydrology 1974: Proceedings of a Symposium, 1974. Vols. 1 and 2.

IKEDA, N. (1949a) Chemical studies on Arima hot springs I. Distribution of hot springs and discussion on Ariake-no-yu. Nippon Kagaku Zasshi 70, 328329.

IKEDA, N. (1949b) Chemical studies on Arima hot springs II. Chemical composition of Ariake-no-yu, Shin-onsen and Hon-onsen. Nippon Kagaku Zasshi 70, 363-366.

IKEDA, N. (1955) Chemical studies on Arima hot springs. III, IV. Chemical composition of Tenmanguyu, Nippon Kagaku Zasshi 76, 716-721.

IKEDA, N., TANAKA, K. and SEKI, R. (1973) Determination of tritium concentration in hot spring water. Radioisotopes 22, 623-627.

Kusakabe, M., Wada, H., Matsuo, S. and Horibe, Y. (1970) Oxygen and hydrogen isotope ratios of monthly collected waters from Nasudake volcanic area, Japan. J. Geophys. Res. 75, 5941-5951.

Matsubaya, O., SAKai, H., Kusaka, I. and Satake, H. (1973) Hydrogen and oxygen isotopic ratios and major element chemistry of Japanese thermal water systems. Geochem. J. 7, 123-151.

Matsubaya, O., SaKaI, H. and Tsurumaki, D. (1974) Hydrogen and oxygen isotopic ratios of hot springs and mineral springs in Arima region. Okayama Daigaku Onsen Kenkyusho Hokoku No. 43, $15-28$.

Miyake, Y., Kitano, Y., Saruhashi, K., Taga, M. and TSUBOTA, H. (1955a) Chemical study on Arima hot springs I. Carbonated Spring Science Research 20-25.

Miyake, Y., Kitano, Y., Saruhashi, K., Taga, M. and Tsubota, H. (1955b) Chemical study on Arima hot springs III. Carbonated Spring Science Research 29-36.

NAKAMURA, H. (1962) Geological studies of hot springs in Japan. Rept. Geol. Survey Japan, No. 192, $73-80$.

NAKAMURA, H. and MAYEDA, K. (1958) Thermal saline waters in Japan. Bull. Geol. Survey Japan 9, $431-440$.

SAKAI, H. and Matsubaya, O. (1974) Isotopic geochemistry of the thermal waters of Japan and its bearing on the Kuroko ore solutions. Econ. Geol. 69, 974-991.

TAGUCHI, Y. and TsuKadA, K. (1972) On the Seranma hot spring in Kuchi-no-shima Island. Hydro$\log y$ No. 5, 14-21.

THEODORSSON, P. (1967) Natural tritium in groundwater studies. (SM-83/26) Isotopes in hydrology. IAEA, 371-380.

Tsunogai, S., Ishida, M. and Kurata, T. (1982) Latitudinal variation of tritium in rain water in Japan. Proc. Annual Meet. Geochem. Soc. Japan, 148-149. 